Journal of English Language Teaching

UNNES

\title{
Undergraduates' use of metacognitive strategies in a PBL writing process
}

\author{
Muhammad Mukhtar Aliyu ${ }^{凶 1}$, Yong Mei Fung ${ }^{2}$ \\ ${ }^{1}$ Bauchi State University, Gadau-Nigeria \\ ${ }^{2}$ Unversiti Putra Malaysia, Malaysia
}

\section{Article Info}

Article History:

Received in 11

September 2020

Approved in 29

November 2020

Published in 30

November 2020

Keywords: metacognitive strategies; Nigeria; PBL; undergraduates; writing

\begin{abstract}
This study examines the use of metacognitive strategies in undergraduates' PBL writing process. The participants of the study are 18 second-year undergraduates in an intact class of Advanced Composition in a university in North-eastern Nigeria. Data for the study were collected through audio and video recordings of the participants' interactions in the PBL process. The findings of the study showed the PBL allowed the participants to effectively use metacognitive strategies: planning, monitoring and evaluation in various ways to achieve their writing goals. For the planning process, the participants made an overall plan of their writing process, generated various ideas, retrieved their rhetorical and linguistic knowledge, and made decisions on what and how to present ideas in their writing. For monitoring, they kept track of the transition of ideas and paragraphs in their writing and identify and remedy problems that affect the writing progress. For evaluation, they evaluated the content, organisation, and language of their writing. The paper makes some recommendations for teachers to assist students in the use of metacognitive strategies which eventually improve their writing skills.
\end{abstract}




\section{INTRODUCTION}

Undergraduates' writing challenges have been documented by numerous studies. Many strategies and approaches have also been proposed to develop the students' writing performance $(\mathrm{Mu}, 2005)$. Some of the strategies that are believed to be useful in developing students' writing performance are metacognitive strategies which enable a writer to regulate their knowledge of the writing process and the different demands of different writing genres (Wong, 1999).

In the writing process, metacognitive strategies are mental procedures used by writers to regulate their writing through planning, monitoring and evaluating (Wenden, 1991; Wong, 1999). The strategies play an important role in the development of students' writing skills $(\mathrm{Mu}, 2005$; Victori, 1999; Wong, 2005); they distinguish successful from less successful writers. Various researchers identified the three main metacognitive strategies which writers use in their writing: planning, monitoring and evaluation (Mu, 2007; Riazi, 1997; Wenden, 1991; Wong, 1999).

Planning involves accessing and retrieving knowledge relevant to a task and making decisions about what to write and how to write (Wenden, 1991). Wenden identifies three types of task knowledge writers need to retrieve to effectively plan their writing. They are: a) world knowledge which is the participants' general knowledge and opinion about the topic; b) rhetorical knowledge which is the knowledge of organising ideas and paragraphs in writing, c) and linguistics knowledge which is the knowledge of grammar and appropriate vocabulary needed to present the ideas in the writing.

In the writing process, Wenden (1991) defines monitoring as a process of overseeing the whole writing process while observing when and why it is being hindered from progress. While she defines evaluation in writing as the process of determining the quality of a written product by looking back to determine the need for revision and making necessary changes. Wenden mentions three types of task knowledge that are necessary for evaluation: i) message knowledge, ii) rhetorical knowledge and iii) linguistic knowledge. Message knowledge is the understanding of what a writer wants to say about a topic based on his/her world knowledge. It allows a writer to see a connection between his/her intent and the written product. Rhetorical knowledge is the knowledge of logical organisation and presentation of ideas in the writing. It helps a writer in evaluating the appropriateness and adequacy of the arrangement of ideas in the written product. Linguistic knowledge includes knowledge of language structure, vocabulary, punctuation and spelling, which allows a writer to correct his/her language-related mistakes.

Many studies show that effective writers use metacognitive strategies which enable them to become successful and better writers. Wei, Shang and Briody, (2012) found that high-level writers employ metacognitive skills more effectively in their writing process, especially during planning reviewing, than low-level ones. For example, the high-level writers generate and organise complete ideas during the planning stage and they are more concerned with the needs of their audience and the demands of specific genres. Rahimi and Katal's (2011) study also showed the relationship between awareness of metacognitive strategies and successful language learning. They observed that metacognitive learners who take conscious steps to understand what they are doing when they learn to tend to be the most successful learners.

Despite the strong positive relationship between the use of metacognitive strategies and students' writing performance, there seems to be a lack of studies that employ approaches that give students ideal contexts, explicit instructions, collaboration, scaffolding and sufficient time to fully utilise the strategies in their writing process. Therefore, this study adopts a Problem-based Learning approach (PBL) to investigate the use of metacognitive strategies in the writing process. In the PBL approach, students are given an ill-structured problem which is complex and related to their real-life situation, which also requires multiple answers. They are allowed to work collaboratively in small groups and in sessions, which allows them to easily master what they learn in every session. Teachers on their parts facilitate the students' learning by explaining their roles and those of the students' and through metacognitive questioning to effectively use the metacognitive strategies for improved performance in the students' writing (Lim, 2012). The study is aimed at answering the following research question: How do the participants use metacognitive strategies in the PBL writing process? 


\section{METHODS}

\section{Respondents}

The participants of the study are 18 second-year students taking Advanced English composition course in a local university in Nigeria. They are of mixed-gender with ages ranging from 24-36 years old. They were selected based on purposeful sampling. Audio-video recording was the main instrument used for the data collection. The participants' interactions during the PBL process were recorded and transcribed verbatim.

\section{Data collection procedures}

To conduct the research, permission was obtained from the Department and every participant signed an informed consent form to give their consent. Before the actual study, the participants were briefed on the concepts of PBL and metacognition. Rehearsal and demonstration on how to carry out the PBL process was conducted.

Two ill-structured problems were given to the participants: the first one is on attacks and abductions of some university students by some terrorist groups in the Northern part of Nigeria which put fear in some parents and students. The second ill-structured problem is about students' poor academic performance and study attitudes as a result of excessive engagement with social media (see Appendix).

The participants were asked to work in small groups and propose viable solutions to the problems in two PBL cycles following Savery and Duffy's (1995) model. In each PBL cycle, the participants worked on one ill-structured problem for three weeks, one session per week for two hours.

The model presents the systematic process as follows: The facilitators identified and designed relevant ill-structured problems and presented to the participants. They also grouped the participants into smaller groups and asked each group to work collaboratively to generate working ideas, identify available information related to the problem; identify learning issues (things about which they need to find out more information); identify resources to look up or consult; assign tasks to each group member (i.e. who will be responsible for working on each learning issue) to gather information (conduct self-directed learning), and finally propose viable solutions.

In the first session, the participants planned how to write viable solutions with the help of a tutor. They followed the PBL steps 1 to 5 to brainstorm and organise the viable solutions to the illstructured problem. They read the ill-structured problems, generated possible causes, solutions and other information related to the problems. The participants also identified things they should know more about to solve the problems (learning issues), and resources to consult to obtain the information through self-directed learning. In the second session, the participants exchanged findings of their self-study with group members. Thereafter, the participants drafted their proposed solutions. During the third session, the participants reviewed what was written in the previous session. They read and reread words, sentences and paragraphs of the drafts and made corrections.

\section{FINDINGS AND DISCUSSION}

To answer the research question of the study, (how do the participants use metacognitive strategies in the PBL writing process), the participants' interactions during the PBL sessions were recorded and transcribed verbatim. The transcripts were coded following Wenden's (1991) model on the use of metacognitive strategies: planning, monitoring and evaluation in the writing process. What the participants did while using each of the strategies are categorised and presented in episodes and supported with the excerpt from their interactions. An episode is defined by Nelson and Carson (1998) as any utterance that is semantically related in topic or purpose.

The episodes occurred in all the three sessions: planning, drafting and reviewing as the use of metacognitive strategies in the writing process was not linear but cyclical. For instance, while generating ideas, the participants might also plan, monitor and evaluate the process. Also, while drafting or reviewing their writing, participants referred to the planning to check for the consistency between what was planned and what was written. The following sections present the episode in all the metacognitive strategies, planning, monitoring and evaluation.

\section{Planning in Writing}

During planning, the participants retrieved their prior knowledge on the ill-structured problems, brainstormed the possible causes and solutions to the ill-structured problems. Following the retrieval 
of knowledge, they made decisions regarding what to include in the writing and how to write. They also retrieved and decided on their rhetorical and linguistic knowledge.

Four episodes emerged from the participants' interactions during planning: a) instructionrelated episode, $b$ ) idea generation episode, c) organisation-related episode and d) language-related episode. The names of the episodes are adopted from previous studies. The instruction related episode and the organisation-related episode were modified from Amirkhiz (2013). The ideageneration episode and the language-related episode are adopted from Swain and Lapkin (1998). The following sections explain the episodes.

\section{Instruction-related Episode}

Amirkhiz (2013) describes instances where learners discuss writing topic and instructions as 'reading the topic and task instructions'. In the current study, Instruction-related episode occurred when the participants initiated their writing activities in a session. It involved reading the ill-structured problems, reading or giving instructions on how to carry out the PBL process.

It also included announcing a specific writing task or goal to undertake at a time. In the instruction-related episodes, the participants made the overall planning of the activities. This allowed them to focus on what exactly they were expected to do in a session. It helped them to better understand the writing topic and set goals about the task. It also allowed them to think and decide on how to accomplish the task and what to include in the writing. It was through the reading instruction and setting guidelines that participants worked out strategies that assisted them through the writing process. This is illustrated in Excerpt 1. The episode occurred when the participants initiated their discussion of the ill-structured problem of terrorism in Northern Nigeria. They discussed how to plan the whole PBL processes.

$\begin{array}{ll} & \text { Excerpt } 1 \\ \text { Yunus: } & \text { Now... we have an ill-structured problem. We are going to brainstorm about and see } \\ & \text { if we can come with possible solutions to it. When we finish everything we are going to } \\ & \text { write a composition on this problem. As a chair, let me remind you something. In this } \\ & \text { group the chair will control the discussions, the secretary will write our points. While } \\ & \text { we are discussing, we will identify possible causes and solutions, and study issues or } \\ & \text { learning issues and possible actions. } \\ & \text { [/Ok } \\ \text { Ummi: } & \text { [/Ok } \\ \text { Amina: } & \text { So now, I will begin with reading the problem. Our ill-structured problem is this, and } \\ \text { Yunus: } & \text { everyone should listen to it attentively. If you have any question regarding it, you ask } \\ & \text { and it gets explained... Any question regarding the understanding of the problem? } \\ \text { Ishaq: } & \text { Actually, no... as far as I'm concerned } \\ \text { Yunus: } & \text { Very straight forward? = } \\ \text { Ishaq: } & \text { Yeah. }=\end{array}$

Yunus who was the Group 1 leader, suggested that they should brainstorm the possible causes and solutions to the ill-structured problem. He began by giving an overview of the process and giving instruction on how to carry out the activities. He then reminded his group members on how the PBL process should be conducted and what they were expected to do. He read out the illstructured problem to the group members and asked if there was anything in need of clarification. Other participants responded positively. By following PBL, it helped to increase the participants' metacognitive awareness, as they became more aware of the need to plan to achieve their writing goals (Ezeanyanike, 2013).

Another example of the instruction-related episode occurred at the beginning of the reviewing session. The participants deliberated on how to carry out the editing process and decided on the exact aspects of the writing to look at and correct. With the help of a tutor, the participants identified criteria for the editing process such as at grammar, spelling, punctuation and organisation of their writing.

\section{Idea-generation Episode}

Swain and Lapkin (1998) categorise any stretch of discourse made by the students when writing, which dealt with the generation of an idea for their writing as 'idea unit'. Idea-generation episode occurred while the participants were retrieving and generating knowledge and ideas related to the ill- 
structured problems, possible causes, effects or solution to the ill-structured problems. It also occurred when the participants decided on what specific causes or solutions to include in their writing. Excerpt 2 illustrates this. In this excerpt, the participants brainstormed viable solutions to the ill-structured problem of why Nigerian undergraduates excessively engage with social media.

\begin{tabular}{|c|c|}
\hline & Excerpt 2 \\
\hline \multirow[t]{2}{*}{ Umar: } & Umm... first of all we have to identify the causes of the problem. \\
\hline & John: $\quad$ Can anybody give us one? \\
\hline Habib: & $\begin{array}{l}\text { But are we looking for the solutions not the causes or? What the question demands us } \\
\text { to do }\end{array}$ \\
\hline Umar: & How can you propose solutions without the causes? \\
\hline Habib: & Hmm (2.0), the cause is too much engagement on internet \\
\hline Umar: & That is not the cause. That is the problem. What causes the problem? \\
\hline Habib: & $\begin{array}{l}\text { Short cuts, they are looking for shortcuts. They don't want to engage in using books or } \\
\text { consulting books }\end{array}$ \\
\hline \multirow[t]{2}{*}{ Umar: } & $\begin{array}{l}\text { Ok, that is one of the causes. One of the causes is that desire to go hand in hand with } \\
\text { the modern world. The students want to go alone with modernity }\end{array}$ \\
\hline & John: $\quad$ Just use one word for it \\
\hline Umar: & When we say modernity... what does it mean? \\
\hline \multirow[t]{3}{*}{ John: } & $\begin{array}{l}\text { If I understand, what you are saying is that the students want to become modern } \\
\text { people }\end{array}$ \\
\hline & Umar: $\quad$ Ok, modernity do you agree? \\
\hline & Justina: $\quad$ Yes, \\
\hline Habib: & I think another factor is socialization, the effect of socialization \\
\hline Umar: & How? I see socialization is part of modernity \\
\hline
\end{tabular}

Umar suggested that they should first identify the causes of the problem. Habib objected that they were asked to provide solutions not causes to the problem. Umar had to explain it to the group that they could only provide viable solutions when they identified the causes of the problem. They all agreed to first think about the possible causes to the problem then suggest viable solutions based on their personal experiences and views. As could be seen from Excerpt 3, the participants generated various causes to the problem such as lack of reading habit among students and the desire to go with the modern world. Having identified the possible causes, they elaborated each of the causes and suggested a viable solution. For example, they suggested that online teaching should be adopted to make learning interesting to students. They further suggested that school managements should regulate the use of the Internet to avoid its abuse by the students. The interactions show that PBL processes involved all the participants in the learning process and encouraged to recall information (Ezeanyanike, 2013) they already acquired related to the problems. Generating ideas also involved the awareness of metacognitive knowledge of task (Wenden, 1991), as the participants generate ideas which are a requirement for the accomplishment of the writing task and decision-making on what to include in the writing.

\section{Organisation-related Episode}

Amirkhiz (2012) describes the organisation of ideas as a collaborative discourse dealing with the organisation and arrangement of ideas in a text. Organisation-related episodes occurred when the participants retrieved their rhetorical knowledge which included knowledge of how to write a title, thesis statement, and link ideas then decided on how to organise their ideas and arrange paragraphs in the writing. Having generated the possible causes and solutions to the ill-structured problem, the participants used their rhetorical knowledge to logically organise and present their ideas into paragraphs in the writing as shown in Excerpt 3. At this point, the participants discussed how to present viable solutions to the problem of terrorism in Northern Nigeria.

\footnotetext{
Excerpt 3

Yunus: $\quad$ Now who will suggest how we will plan the essay because we should draft now?

Amina: $\quad$ The essay should take steps, from introduction, then the body, main issues there and we will give our recommendation or solutions then conclusion.
} 


\begin{abstract}
Yunus: $\quad$ So, I think paragraph one is introduction. Write it in our outline. Ishaq: What shall we write in the introduction?

Yunus: $\quad$ For the introduction, we... we give background of the problem. So that who doesn't know the situation now, in the introduction, he should know the situation, like the problem given to us has explained the situation.

Amina: $\quad$ In the body... how do we do this? Are we going to mention the cause's solution or we mention the causes then we have some other paragraphs to explain the solution?

Abubakar: I suggest that, lets mention the causes then later, the solutions
\end{abstract}

In Excerpt 3, the participants showed their understanding of the need to arrange and present their ideas in a manner that would be meaningful to the reader. First, Amina suggested that their writing should have three parts, viz: i) the introduction, ii) the body where they would discuss the causes and solutions of terrorism, and ii) the conclusion respectively. All other participants agreed to present the ideas in that order. Also, Yunus suggested that an overview and background information to the ill-structured problem of terrorism in Northern Nigeria should be presented in the introductory paragraph. In the body of the essay, Yunus further suggested that each possible cause with its viable solutions should be presented in a paragraph of its own. This opinion was not agreed upon by Abubakar, who suggested that they should divide the body into two parts. In the first part, each of the causes of terrorism should be presented in a paragraph. In the second part, each possible solution to terrorism should also be presented in a paragraph. This suggestion was agreed upon by all the group members.

These interactions, as presented in Excerpt 3, have proven that rhetorical knowledge is a prerequisite for planning writing activities. This is the knowledge they acquired on how to translate their ideas into writing and present it to the audience. It involves a decision on where and how to put and develop every idea from the overall composition to a single paragraph (Wenden, 1991).

The process also reveals how the PBL approach helped the participants to be more aware of the need for proper organisation in their writing. It also helped them to learn strategies on how to arrange and, logically, present their ideas.

\title{
Language-related Episode
}

Swain and Lapkin (2002) define language-related episode as any group of utterances or segment of dialogue in which group members talk about the language they produced, correct themselves, or reflect on their use of language. In this study, language-related episodes occurred when the participants retrieved their linguistic knowledge and determined the accurate and appropriate language to use in their writing. This includes grammatical accuracy, tense, word order, articles, appropriate words and expressions. Excerpt 4 is an example of a language-related episode from the participants' interactions. The participants were deliberating on the ill-structured problem of terrorism in Northern Nigeria. 
Umar described how the terrorists involved children in their activities. He used the words lured or forced to show that the children were involved in the activities unwillingly. John suggested that the word innocent should be added to qualify the children. Umar then suggested a more suitable word entice to substitute lured. However, Justina raised observation on the use of the words enticed and unwillingly in the same sentence. She pointed out that the two words have opposite meanings; therefore, both cannot be possibly used within the same expression. However, Umar suggested that they should check their dictionary after which they agreed on the appropriate word to use. This indicates how the PBL approach allowed the participants to deliberate on their language and to use appropriate words to express their ideas in a writing process. This shows how the PBL approach allowed the participants to think from their previous knowledge and to build from the knowledge of others to improve their language writing.

\section{Monitoring in the Writing Process}

Monitoring is the process where the participants kept track of their progress from one stage of writing to another while identifying any problem that hinders the writing progress. Two episodes related to monitoring were identified during the PBL writing process: the transition-related episode and the problem-recognition episode. The names of the episodes emerged from this study based on Wenden's (1991) model.

\section{Transition-related Episode}

The transition-related episode occurred when the participants kept track of their writing progress from one aspect or stage of writing to another by announcing the writing stage they were at or heading towards. For instance, they checked their progress and decided when to stop generating ideas and start writing. Also, during writing, they made sure the sequence of the paragraphs in the outline was followed while drafting viable solutions. They also decided on when to end a paragraph and start a new one. While reviewing the writing, they checked to ensure that all their ideas were included in writing. Excerpt 5 is an example showing how the participants monitored the progress of their writing process. The excerpt occurred after the participants exchanged the findings of their selfstudy to their group. The participants agreed to draft their proposed solutions.

$\begin{array}{ll} & \text { Excerpt } 5 \\ \text { Amina: } & \text { The next thing is writing an essay. We are done with the learning issue. } \\ \text { Abubakar: } & \text { We have already drafted an outline. Amina, bring it. We have all the causes to the } \\ & \text { problem outlined and the proposed solutions. } \\ & \text { Tutor: } \quad \text { Do you all agree with the outline? } \\ & \text { Ishaq: } \quad \text { Yes, we do } \\ & \text { Abubakar: Ok, let's start writing } \\ & \text { Yunus: Binta, you can write for us. } \\ \text { Binta: } \quad \text { Ok. } & \\ \text { Abubakar: } & \text { Let's follow it and exhaust all the causes and the solutions then we go back and edit. } \\ \text { Ishaq: } & \text { Yes, if there is any addition or subtraction we do that after. }\end{array}$

Amina, who was the group leader in the session, announced that they should start drafting. Abubakar suggested that they should follow their outline, which is the list of the possible causes and the viable solutions to the problem of terrorism in Northern Nigeria then the possible solutions. Abubakar further suggested that while drafting their essay, they should present the causes and the solutions to the problems. They should not mind editing the work at that moment since they could edit and rewrite it in the subsequent session. These interactions indicate that the PBL approach helped the participants to monitor their writing progress. As Amina pointed out that they should stop generating ideas and start drafting the essay, they became more aware of the whole writing process. This is shown where Abubakar emphasised that the outline should be followed and reminded them that they could edit and rewrite the essay afterwards. This also shows that PBL heightened the participants' awareness as they determined when to begin or to stop a process as well as what enough is or not.

\section{Problem-recognition Episode}

The problem-recognition episode occurred when the participants identified a problem or acknowledged that they had a problem executing some aspects of their writing. For example, when 
they were confused about a word, or had an idea, but did not know how to present the idea. These are identified as problem-recognition episodes. This is illustrated in Except 6 below. The episode occurred while the group members were drafting possible solutions to the second ill-structured problem of the Nigerian undergraduates' excessive engagement with social media. The participants identified an obstacle to the writing process.

$\begin{array}{ll} & \text { Excerpt } 6 \\ \text { Umar: } & \text { Now the problem is how we link modernity with our topic. We have now defined } \\ & \text { modernity but how does it contribute to the undergraduates' excessive engagement } \\ & \text { with social media? = } \\ & \text { Habib: } \\ \text { Everyone wants to go hand in hand with modernity } \\ \text { Umar: } & \text { Everybody wants to break from the bounds of tradition and pre-modern system } \\ \text { Umar: } & \text { That is why anything that regarded as modern is blindly accepted at the expense of its } \\ & \text { impact whether it is negative or positive. So how do we link it for example the } \\ & \text { possession of handset and registering or joining of social media? } \\ \text { Habib: } & \text { Nowadays (...) everybody possess handset just to be part of modernity } \\ & \text { Umar: } \quad \text { Yes, not only because of communication } \\ & \text { Yes, not only because of communication but because they want to go hand in hand } \\ & \text { with modernity. They don't want to be called a primitive person. Also engaging in } \\ & \text { social media is now a treat. }\end{array}$

During the idea-generation process, they identified modernity as one of the factors that caused the Nigerian undergraduates to engage excessively with social media. However, while drafting they did not know how to present it in the writing to show its connection with the problem of students' excessive engagement with social media. This was pointed out by Umar. After the long discussions, they realised how modernity is linked to the problem. Umar mentioned that undergraduate students considered social media as part of modernity. Thus, they blindly embraced it without considering its negative consequences. At this point, the interactions indicate that PBL process has encouraged the participants to collaborate, pull ideas from one another to identify and solve problems in their writing process.

\section{Evaluation in the Writing Process}

Evaluation is the process where the participants reviewed their proposed solutions to the illstructured problems by rereading words, sentences, paragraphs. In the process, they referred to the knowledge (world knowledge, rhetorical knowledge and linguistic knowledge) they retrieved during planning to improve the content, clarity, organisation, grammar, vocabulary, spelling, and punctuation of the proposed solutions.

Three episodes emerged from the evaluation process: content-related episodes, organisationrelated episodes, and language-related episodes. Both the content-related episode and the organisation-related episodes are modified from Amirkhiz's (2012) clarification of content and organisation of ideas. On the other end, the language-related episode is adopted from Swain and Lapkin (1998). The following sections present the episodes with examples from the participants' interactions.

\section{Content-related Episode}

Amirkhiz's (2012) describes the clarification of content as learners' collaborative discourse dealing with the content of their writing. In this study, content-related episodes occurred when the participants accessed their message knowledge, which is their understanding of what they wanted to say about the ill-structured problem and compared it to the written viable solutions to make corrections. Excerpt 7 is an example of how the participants evaluated the content of their writing. In the episode, the participants reviewed the written viable solutions to the problem of terrorism in Northern Nigeria. The participants referred to their brainstorming and checked the plausibility and viability of the solutions generated and compared them with the text.

\section{Excerpt 7}


Umar: Let us look at our introduction. We said we should start by defining the key terms, which are the social media and undergraduate students. Because they are regarded as the main issue in the topic

Umar: $\quad$ Babayo: $\quad$ That day we mentioned different definitions of social media. First, we said it is networking site that brings friends, family etc together. Second, we said use of different media for communication. Third, we said societal mass communication. Lastly, we merged the definitions to come with one that is better.

Habib: $\quad Y e s, \quad$ we also need to include the verses that talk of the consequences.

In Excerpt 9, Umar suggested that they should refer to their outline to see the list of the possible causes and solutions generated during the brainstorming session. That helped them to see whether all the ideas generated were included orderly as in the outline or otherwise. Umar reminded them that they agreed to begin the essay by defining key terms. Therefore, he read the introductory paragraph to check whether the key terms were defined. It was found that the paragraph needed to be rewritten. Habib then suggested that some verses from the two holy books, the Bible and the Quran, should be used to support their claims that terrorism is evil since most of their readers practise either Christianity or Islam. The interactions have confirmed the claim on the importance of content knowledge in evaluating one's writing (Wenden, 1991).

\section{Organisation-related Episode}

According to Amirkhiz (2013) organisation of ideas is a collaborative discourse dealing with the organisation and arrangement of ideas in a text. In this study, organisation-related episodes occurred when the participants used their rhetorical knowledge to evaluate the appropriateness and accuracy of the organisation and arrangement of ideas in their writing. This episode occurred during both the planning and the evaluation.

\section{Language-related Episode}

Swain and Lapkin (2002) describe the language-related episode as any group of utterances or segment of dialogue in which group members talk about or reflect on the language they produced and correct themselves. In this study, language-related episodes occurred when the participants used their linguistic knowledge to evaluate the accurateness and appropriateness of the language used in the written product. They reviewed the writing and corrected their language-related mistakes. This included tense, word order, articles, word and expression choices, spelling and punctuations. This episode also occurred at planning.

\section{Discussion}

The findings of the study showed that PBL encouraged the participants to use metacognitive strategies in various ways to achieve their writing goals. For the planning process, the participants made an overall plan of their writing process, generated various viable solutions to the ill-structured problems, retrieved their rhetorical and linguistic knowledge, and made decisions on what and how to present ideas in their writing. In the monitoring process, PBL allowed the participants to keep track of their writing process, identify and solve any problem that would hinder the process. During the evaluation process, the interactions enabled them to review their writing output to evaluate the content, organisation and the language used. It is further shown that the use of metacognitive strategy in the participants' writing process was not linear; it was cyclical. For instance, while generating ideas, the participants planned, monitored and evaluated the process. Also, while drafting or reviewing their writing, the participants referred to the planning to check for consistency between the ideas outlined during the planning and the written product.

These results are in line with most of the recommendations of Graham and Harris (2009), and Xiao (2007) on how to develop students' metacognition and writing skills. Those studies pointed out that instructors should, among other things, engage and support learners in the writing process, provide ample time for writing and allow them to monitor their writing performance. Instructors should also incorporate instructional procedures that allow learners to work together to plan, draft, revise, and edit their writing.

It was further revealed from the study that the PBL approach is effective in allowing the participants to be aware of the task knowledge, which is essential in using the metacognitive strategies (Wenden, 1991). This was possible because the PBL approach encouraged the participants 
to learn collaboratively by sharing and exchanging ideas. They gathered more information from their various personal experiences. This is in line with findings of Beebe and Masterson (2003) that in a collaborative learning process, groups have more information than a single individual does. The results also confirm Wenden's $(1991,1998)$ study that to accomplish writing goals, writers need to be aware of the need to use their metacognitive task knowledge.

\section{CONCLUSION}

The study aims to examine how the participants use metacognitive strategies in the PBL writing process. The findings reveal that the participants used metacognitive strategies: planning, monitoring and evaluation in various ways which helped them to achieve their writing goals. For the planning process, the participants made an overall plan of their writing process, generated various ideas, retrieved their rhetorical and linguistic knowledge, and made decisions on what and how to present ideas in their writing. For monitoring, they keep track of the transition of ideas and paragraphs in their writing and identify and remedy problems that affect the writing progress. For evaluation, the evaluated the content, organisation, and language of their writing. There are some limitations to the study which could affect the generalizability of the findings. The number of participants is very small and the participants have almost the same characteristics. The intervention period is also not very long. Future studies can select a larger number of participants and administer the PBL treatment of a longer period. Despite the limitations and other challenges, the study has provided teachers with an approach that can motivate students to use metacognitive strategies in the writing process which in turn enhance their writing performance.

\section{REFERENCES}

Amirkhiz, S. Y. Y. (2013). Cross-cultural variations in ESL/EFL female learners' product, process and perceptions in collaborative task. Unpublished $\mathrm{PhD}$. Thesis, Univerisiti Putra Malaysia.

Ezeanyanike, P. A. (2013). Assessing benefits of collaborative learning environment for quality Higher education in Nigeria. Journal of Educational and Social Research, 3(6), 85-94.

Flavell, J. H. (1979). Metacognition and cognitive monitoring: A new area of cognitivedevelopmental inquiry. American Psychologist, 34(10), 906-911.

Flavell, J. H. (1976). Metacognitive aspects of problem solving. In L. B. Resnick (Ed.). The nature of intelligence. Hillsdale, New Jersey: Erlbaum.

Flavell, J. H. (1987). Speculation about the nature and development of metacognition. In F. E. Weinert \& R. H. Kluwe (Eds.), Metacognition, motivation and understanding (pp. 21-29). Hillsdale, New Jersey: Lawrence Erlbaum Associates.

Flavell, J. H. (1981). Cognitive monitoring. In W. P. Dickson (Ed.), Children's oral communication skills (pp.35 - 60). New York: Academic Press.

Flavell, J. H. (1992). Metacognition and cognitive monitoring: A new area of cognitivedevelopmental inquiry. In T. O. Nelson (Ed.), Metacognition: Core readings (pp. 3-8). Boston: Allyn \& Bacon.

Graham, S., \& Harris, K. R. (2009). Evidence-based writing practices: Drawing recommendations from multiple sources. British Journal of Educational Psychology 6, 95-111.

Hyland, F. (2000). ESL writers and feedback: Giving more autonomy to students. Language Teaching Research, 4(1), 33-54.

Lim, W. K. (2012). Dysfunctional problem-based learning curricula: Resolving the problem. BMC Medical Education, 12 (1), 89.

$\mathrm{Mu}, \mathrm{C}$. (2005). A taxonomy of ESL writing strategies. Proceedings of Redesigning Pedagogy: Research, Policy, Practice, (pp. 1-10). Singapore, Newman.

Oxford, R. (2002). Language learning strategies. In R. Carter and D. Nunan (Eds.), The Cambridge guide to teaching English to speakers of other languages (pp. 166-172). Cambridge: Cambridge University Press.

Rahimi, M., \& Katal, M. (2012a). Metacognitive listening strategies awareness in learning English as a foreign language: a comparison between university and high-school students. Procedia - Social and Behavioral Sciences, 31(2011), 82-89.

Rahimi, M., \& Katal, M. (2012b). Metacognitive strategies awareness and success in learning English as a foreign language: An overview. Procedia - Social and Behavioral Sciences, 31, 73-81. 
Riazi, A. (1997). Acquiring disciplinary literacy: A social-cognitive analysis of text production and learning among Iranian graduate students of education. Journal of Second Language Writing, 6(2), 105-137.

Savery, J. R., \& Duffy, T.M. (1995). Problem-based learning: An instructional model and its constructivist framework. In Brent G. Wilson (Ed.) Constructivist learning environments: Case studies in instructional design. New Jersey: Educational Technology Publications.

$\mathrm{Su}, \mathrm{Y}$., (2007). The Impact of scaffolding type and prior knowledge in a hypermedia, problem-based learning environment. Unpublished Ph.D. thesis, Arizona State University.

Victori, M. (1999). An analysis of writing knowledge in EFL composing: A case study of two effective and two less effective writers. System, 27, 537-555.

Wenden, A. L. (1998). Metacognitive knowledge and language, Applied Linguistics 19(4), 515-537.

Wenden, A. (1991). Metacognitive strategies in L2 writing: A case for task knowledge. In A. James (Ed.), Georgetown university round table on languages and linguistics (pp. 303- 322). Washington, DC: Georgetown University Press.

Wong, B. (1999). Metacognition in writing. In R. Gallimore, L. P. Bernheimer, D. L. MacMillan, D. L. Speece, \& S. Vaughn (Eds.), Developmental perspectives on children with high-incidence disabilities (pp. 183-198). Mahwah. New Jersey: Erlbaum. 


\section{APPENDIX}

\section{Ill-structured Problems}

Problem 1 (First PBL cycle)

The recent attacks and abductions of some university students by some terrorist groups in the northern part of the country and the involvement of some university students in terrorism have put fear in some parents and students. This has caused some students, particularly those in that part of the country to transfer their scholarship to other universities while others even abandon schooling completely. What do you think could be done to solve the problem?

Collaboratively discuss the problem in your groups following the PBL steps and propose viable solutions to the problem. You are given three weeks to work on the problem with your group members and come up with proposed solutions to the problem.

\section{Problem 2 (Second PBL cycle)}

In recent years, parents, lecturers and government have shown their concern over the poor academic performances and study attitudes of Nigerian undergraduates. Excessive engagement of social media by the undergraduate students has been identified as one of the contributing factors to the menace. A recent study by Okechukwu and Ngozi, (2014) has shown that majority of Nigerian undergraduates engage in at least two and above forms of social media. It has been observed that most of the students spend much of their times on the internet instead of studies. On average, the students spent 6-7 hours on social media a day, as a result, it affects their academic performances and study attitudes negatively.

Propose viable solutions to address this problem following the PBL steps. You are given three weeks to work on the problem with your group members and come up with proposed solutions. 